\title{
INHIBITING PSEUDOMONAS AERUGINOSA GROWTH ASSOCIATED WITH PROSTHETIC LINERS
}

\author{
John D. Jarrell ${ }^{* 1,2,3,4,5}$, Dioscaris R. Garcia ${ }^{1,2,5}$, Christopher T. Born, ${ }^{1,2,4,5}$ \\ ${ }^{1}$ Alpert Medical School at Brown University, Rhode Island, USA. \\ ${ }^{2}$ RI Hospital, USA. \\ ${ }^{3}$ Materials Science Associates, USA. \\ ${ }^{4}$ BioIntraface, USA. \\ ${ }^{5}$ BI Medical LLC, USA. \\ *Email: johnjarrell@materialsscience.org
}

\section{INTRODUCTION}

The conventional use of a prosthetic device by amputees involves contact of the residual limb tissue with the prosthetic socket using an intermediate elastomer liner. Roll-on gel liners are applied directly to the limb, and slide into the rigid hard socket; the gels are generally silicone or plastic. Regardless of the material, or the liner system used on a residual limb, problems occur because of direct skin and socket or liner contact ${ }^{1}$. The skin tissue of the residual limb is subject to compressive, shear, and tensile forces through weight bearing against the interface wall. In addition the skin is subject to heat/sweat issues that may be seasonal and related to the insulation properties of the interface material. A common problem encountered by the prosthetic user is socket odor, or odor emanating from socket liners ${ }^{2}$. Proper hygiene does not guarantee the reduction of strong socket or liner odor over time. In addition, skin problems among amputees include rashes, blistering, mold/fungal infections and other skin irritations. The socket/wall interface (regardless of material composition) is subject to local skin sloughing, sweat, and skin oils in a warm/moist dark environment over hours of use providing an ideal environment for fungal and bacterial growth $^{3}$. To address this problem, our team evaluated a titanium and silicone hybrid cleaning and coating technology containing a silver fatty acid complex against the odor producing, Gram-negative, facultative anaerobe, Pseudomonas aeruginosa ${ }^{4}$.

\section{METHODS}

The Kirby Bauer assay using Pseudomonas aeruginosa was performed to test for the antimicrobial properties of standard prosthetic liner compared to liners cleaned and coated with a titanium - silicone forming solutions dope with various levels of a silver-fatty acid complex (Apocrine $^{\mathrm{TM}}$, BI Medical, Coventry, RI).
A lawn of bacteria was inoculated over tryptic soy agar. Circular plugs were punched out of various liner materials and placed with the gel side in contact with the agar. Coated and non-coated samples were used with $100 \%$ silver controls. The plate was incubated for 48 hours at $37 \mathrm{oC}$ and the assay was recorded every 24 hours via photography to measure the zone of bacterial growth inhibition.

\section{RESULTS}

No inhibition of bacteria was seen with uncoated liners against Pseudomonas aeruginosa in a Kirby Bauer assay. The zone of inhibition increased with increasing levels of silver complex. Interestingly, the uncoated hybrid liner material showed an increased halo of bacterial growth associated with the residual lubricant. This phenomenon was also observed in silicone liner materials, but was inhibited by the cleaning and coating process.

\section{CONCLUSION}

During the testing of various liner materials cleaned and coated with a silver complex doped titanium and silicone hybrid in a Kirby Bauer bacterial-inhibition assay versus Pseudomonas aeruginosa, it was evident that the control (uncoated) materials of hybrid and silicone composition were surrounded by a very dense concentration of bacteria. This phenomenon was evident after 24 hours of incubation at $37 \mathrm{oC}$, but was very noticeable after $48 \mathrm{hrs}$ incubation even with the almost colorless properties displayed by $P$. aeruginosa in this assay. No other material tested displayed this phenomenon for the duration of the study. This observation suggests the possibility of a lubricating agent leaking out of the

silicone and hybrid liner materials, which act as a chemoattractant for the bacteria. In essence, these results displayed the complete opposite effect from the treated 
materials, which showed a halo of bacterial inhibition surrounding their surface.

\section{SIGNIFICANCE}

The result of increased bacterial growth around the uncoated liner material is of particular importance due to the potential impact that the phenomenon could have with the stump-liner interface. If the liner is releasing a bacterial chemo-attractant, it could paradoxically potentiate an already favorable microenvironment to bacterial and fungal growth within the stump-liner interface. These findings may help explain prosthetic liner odor and stump irritation/infection even in the presence of good hygiene. Effective cleaning and coating of prosthetic liners with liquid titanium-silicone-silver complexes is an available approach to reducing the odor associated with liner use.

\section{REFERENCES}

1. Levy SW. Skin problems of the leg amputee. Prosthet Orthot Int. 1980;4:37-44. DOI:10.3109/03093648009103113

2. Koc E, Tunca M, Akar A, Erbil AH, Demiralp B, Arca E. Skin problems in amputees: a descriptive study. Int. J. Dermatol. 2008;47:463-6. DOI: $\quad \underline{10.1111 / \mathrm{j} .1365-}$ 4632.2008.03604.x

3. Köhler P, Lindh L, Bjorklind A. Bacteria on stumps of amputees and the effect of antiseptics. Prosthet Orthot Int. 1989;13:149-51. DOI:10.3109/03093648909079424

4. Jarrell JD, Dolly B, Morgan JR. Rapid screening, in vitro study of metal oxide and polymer hybrids as delivery coatings for improved soft-tissue integration of implants. J BIOMED
MATER
RES
Part
A.
2010;92:1094-104

DOI:10.1002/jbm.a.32435

\section{DISCLOSURE}

Authors have a financial interest and are consultants for BI Medical. $1^{\text {st }}$ and $3^{\text {rd }}$ authors have a financial interest and consult for BioIntraface, Inc. 